\title{
Avaliação da compreensão de surdos através de fábula em Libras
}

\author{
Assessment of comprehension of deaf people by fable in Brazilian Sign \\ Language
}

Evaluación de la comprensión de personas sordas por fábula en Lengua de Señas Brasileña

\author{
Mariana Peres de Morais \\ Doutoranda na Universidade Federal de São Carlos, São Carlos, São Paulo, Brasil. \\ marianaperesm@gmail.com \\ ORCID - https://orcid.org/0000-0003-2254-9419 \\ Cristina Broglia de Feitosa Lacerda \\ Professora doutora na Universidade Federal de São Carlos, São Carlos, São Paulo, Brasil. \\ cbflacerda@gmail.com \\ ORCID - https://orcid.org/0000-0002-3250-1374
}

Recebido em 21 de março 2020

Aprovado em 15 de junho de 2020

Publicado em 8 de julho de 2020

\section{RESUMO}

Nos últimos anos, o impacto de propostas direcionadas ao incentivo de programas para a educação bilíngue de surdos penetraram as instituições brasileiras com o objetivo de estimular o público surdo a alcançar a qualidade de ensino. Muitas pesquisas sobre bilinguismo, aquisição da linguagem e letramento são fundamentais para o desenvolvimento de políticas linguísticas que possibilitem aos surdos formarem-se como cidadãos. Por esse viés, torna-se relevante utilizar práticas pedagógicas competentes para avaliá-los. Porém, no que diz respeito à avaliação de desempenho escolar, encontra-se com mais facilidade na literatura, materiais avaliativos dirigidos para a língua escrita do que aqueles voltados para as línguas de sinais. Pensando nisso, esta pesquisa tem como objetivo avaliar a compreensão em língua brasileira de sinais (Libras) de surdos por meio de uma fábula apresentada em Libras. Para isso, foi realizada uma pesquisa descritiva com participantes surdos residentes na região central do Estado de São Paulo, com idades entre 14 a 18 anos. Os resultados colaboram para o entendimento de aspectos que podem constituir-se como dificuldades/barreiras de compreensão da língua, e de aspectos que podem figurar como facilitadores para a compreensão discursiva. Além disso, os resultados podem ainda colaborar para o aperfeiçoamento da ferramenta de avaliação da compreensão em Libras. Esse entendimento pode auxiliar professores que atuam com alunos surdos na criação de estratégias visando o desenvolvimento linguístico do seu alunado.

Palavras-chave: Educação Especial; surdez; avaliação; Libras. 
http://dx.doi.org/10.5902/1984686X43044

\section{ABSTRACT}

In recent years, the impact of proposals aimed at encouraging programs for the bilingual education for the deaf entered Brazilian institutions with the objective of encourage deaf audiences to achieve teaching quality. Lots of research on bilingualism, language acquisition and literacy are fundamental to the development of language policies that enable deaf people to form themselves as citizens. For this reason, it becomes relevant to use competent pedagogical practices to evaluate them. However, with regard to the evaluation of school performance, there is more easily in the literature, assessment materials directed at the written language than those focused on sign languages. With this in mind, this research aims to objective to evaluate the understanding in Brazilian Sign Language of the deaf through a fable presented in Brazilian Sign Language. For this, a descriptive research was carried out with deaf participants residents in the central region of the State of São Paulo, aged 14 to 18 years. The results of this research work allowed to identify and analyze strengths and weaknesses of sign language users, in the aspects of understanding in Libras. That knowledge can help teachers who work with deaf students to create strategies aimed at the linguistic development of its students.

Keywords: Special Education; deaf person; evaluation; Brazilian Sign Language.

\section{RESUMEN}

En los últimos años, el impacto de las propuestas dirigidas a fomentar programas para la educación bilingüe para sordos ingresó a las instituciones brasileñas con el objetivo de alentar al público sordo a lograr una calidad de enseñanza. Mucha investigación sobre el bilingüismo, la adquisición del lenguaje y la alfabetización son fundamentales para el desarrollo de políticas lingüísticas que permitan a las personas sordas formarse como ciudadanos. Por esta razón, se vuelve relevante utilizar prácticas pedagógicas competentes para evaluarlos. Sin embargo, con respecto a la evaluación del rendimiento escolar, hay más fácilmente en la literatura, materiales de evaluación dirigidos al lenguaje escrito que aquellos enfocados en lenguajes de señas. Con esto en mente, esta investigación tiene como objetivo evaluar la comprensión en Lengua de señas brasileña de los sordos a través de una fábula presentada en libras. Para esto, se realizó una investigación descriptiva con participantes sordos residentes en la región central del estado de São Paulo, de 14 a 18 años. Los resultados de este trabajo de investigación permitieron identificar y analizar fortalezas y debilidades de usuarios de lenguaje de señas, en los aspectos de comprensión en Lengua de señas brasileña. Este el conocimiento puede ayudar a los maestros que trabajan con estudiantes sordos a crear estrategias orientadas al desarrollo lingüístico de sus alumnos.

Palabras clave: Educación Especial; persona sorda; evaluación; Lengua de Señas

Brasileña.

\section{Introdução}

No Brasil, a educação de surdos e pessoas com deficiência auditiva com idade de zero a dezessete anos é prevista em escolas inclusivas e classes bilíngues, conforme consta nos termos do artigo 22 do Decreto $n^{\circ} 5.626$, de 22 de dezembro de 2005. Sendo a modalidade de educação bilíngue, em Língua Brasileira de Sinais - Libras, como primeira língua e a 
http://dx.doi.org/10.5902/1984686X43044

modalidade escrita da Língua Portuguesa como segunda língua, segundo a Lei no 13.005/2014, que aprova o Plano Nacional de Educação (BRASIL, 2014).

Entretanto, a luta da Comunidade Surda pela aprovação de ensino bilíngue não é recente. Desde a década de 1990 (SKLIAR, 1998; QUADROS, 1997), o impacto de propostas direcionadas ao incentivo de programas para a educação bilíngue de surdos penetraram as instituições brasileiras. Por esse motivo, as revisões literárias têm apresentado trabalhos científicos, que investigam o ensino bilíngue para surdos, baseados na língua de sinais como foco central nas práticas de ensino, respaldadas pela legislação atual (LACERDA; SANTOS; LODI; GURGEL, 2016; MULLER; STURMER; KARNOPP, 2013; LOPES, 2007; MORGAN, 2005; HOFFMEISTER, 2000).

Tais pesquisas partem do pressuposto de estimular o público surdo a alcançar a qualidade de ensino destacando o papel da Libras para o acesso à leitura e escrita. Nesse sentido, as "pesquisas sobre bilinguismo, letramento e compreensão leitora são imprescindíveis na construção de políticas linguísticas, que permitam aos surdos formaremse como cidadãos" (SILVA, 2015, p. 287). Por esse viés, torna-se relevante utilizar práticas pedagógicas competentes para avaliá-los. No entanto, ao tratar a perspectiva de avaliação de desempenho escolar, a literatura atual apresenta a escassez de instrumentos especialmente produzidos para avaliar a compreensão na Libras, com pouca exploração de recursos avaliativos no que diz respeito à compreensão textual (QUADROS; CRUZ, 2011). Encontram-se com mais facilidade pesquisas que tratam de materiais avaliativos dirigidos para as línguas orais do que aqueles voltados para as línguas de sinais. Todavia, isso "não acontece apenas no Brasil, como em outros países ainda há a necessidade de promoção de pesquisas para o desenvolvimento de instrumentos avaliativos em língua de sinais" (BARBOSA; LICHTIG, 2014, p. 23).

Para Barbosa e Lichtig (2014), a maioria dos estudos abordam instrumentos avaliativos a partir da expressão de língua oral pelo aluno surdo por meio de atividades diversas, sem apresentar um estudo específico dirigido à compreensão textual dos usuários de línguas de sinais. Tal concepção foi verificada através de uma revisão sistemática por assunto no portal de periódicos CAPES (Coordenação de Aperfeiçoamento de Pessoal de Nível Superior), a qual delimitou as publicações de artigos científicos nos últimos dez anos que contivessem os termos: "Avaliação", "Compreensão" "Textos" e "Libras”. A busca resultou em 54 trabalhos, cuja leitura do título e resumo de cada artigo indicou o descarte daqueles que não se encaixavam na temática da revisão, resultando em apenas dois artigos abordando 
http://dx.doi.org/10.5902/1984686X43044

instrumentos avaliativos sobre a compreensão de textos por pessoas surdas, sendo um utilizando crianças surdas como participantes e o outro utilizando surdos universitários. Ambos estudos apoiavam-se em textos em língua portuguesa como segunda língua para surdos. De fato, é importante avaliar como está a compreensão dos surdos relativa a textos escritos produzidos na língua dominante da sociedade a qual ele pertence, sendo esta sua segunda língua. Porém, além disso, não se pode negligenciar a averiguação de como está a compreensão de textos elaborados em sua primeira língua, que servirá de base para a construção de conhecimentos em sua segunda língua. Pois, como é possível aos professores identificar e analisar os pontos fortes e fracos do seu alunado nos aspectos de entendimento na língua brasileira de sinais? Afinal, qual o sentido de identificar se o aluno realmente compreendeu o texto em Libras avaliando-o em outra língua senão a dele?

Se as atividades são apresentadas em sua língua de conforto (Libras), é fundamental que a avaliação de compreensão desse texto também esteja elaborada em sua primeira língua. Diante disso, a condição de utilizar "a libras como instrumento de avaliação é imprescindível para os alunos surdos, pois é esta a primeira língua deles, e é ela que servirá de base para a aquisição dos demais conceitos escolares" (LACERDA, et al., 2019, no prelo).

Pensando nisso, esta pesquisa tem como objetivo avaliar a compreensão em Libras de surdos por meio de uma fábula apresentada em Libras. A escolha de utilizar a fábula como instrumento de coleta de dados é baseada na concepção de que esse tipo de texto é capaz de atingir um público de ampla faixa etária; apresenta cenas vividas por animais, plantas ou objetos, ilustrando virtudes e defeitos do caráter humano, configurando-a como um texto que possui atratividade e desperta a atenção por seu caráter lúdico e fantasioso (ANTUNES, 2007).

Portanto, utilizar a fábula como instrumento de coleta de dados engendra propriedades interpretativas e oferece vastos mecanismos capazes de indicar como os surdos têm compreendido textos elaborados a partir da língua de sinais. Espera-se, com este estudo, promover parâmetros para discussões futuras em relação ao uso da Libras como primeira língua no cenário avaliativo de compreensão textual.

\section{Percurso Metodológico}

Este estudo faz uso da abordagem qualitativa, do tipo descritiva, como forma de perceber e compreender os acontecimentos por meio do conhecimento da descrição da realidade. Segundo Vergara (2000, p.47), a pesquisa descritiva expõe as características de 
http://dx.doi.org/10.5902/1984686X43044

determinada população ou fenômeno, estabelece correlações entre variáveis e define sua natureza.

Para este trabalho foi necessário que os participantes atendessem os seguintes critérios de inclusão: ser surdo; usuários de Libras; ter idade entre 14 e 18 anos e residir no interior do estado de São Paulo. Desse modo, foi possível entrar em contato com os participantes através de associações de surdos de municípios do interior do Estado. Oito surdos participaram deste estudo: cinco do sexo feminino e três do sexo masculino. $O$ instrumento utilizado para a coleta de dados foram vídeos com uma fábula narrada em Libras "A tartaruga e a águia"1 (versão 1 e versão 2) e gabaritos (Gversão 1 e Gversão 2) para anotação das respostas relativas à compreensão da fábula (LACERDA, et al., 2019, no prelo). O vídeo com a fábula em Libras consiste em instrumento avaliativo da compreensão em língua brasileira de sinais, não constando qualquer informação adicional de imagens ou ilustrações e, cada uma das versões, foi narrada por um professor surdo adulto de língua brasileira de sinais. Tais vídeos foram elaborados em duas versões: Uma versão (V2) foi pensada para ser usada com surdos mais jovens, com menos contato com a Libras e a outra versão (V1) pensada para ser usada com jovens com um conhecimento mais consolidado em Libras.

Na versão 1, o professor convidado opta por uma forma mais objetiva de narrar, usando sinais mais precisos, com poucas expansões, contudo sem perder a riqueza de informação da fábula, ocupando na maior parte do tempo a posição de narrador e utilizando menos a estratégia de incorporação de personagens. Na versão 2, a qual consideramos inicialmente menos complexa, o professor convidado optou por apresentar a narrativa através de uma sinalização mais descritiva, com maior expansão dos sinais, de forma mais detalhada, maior uso de incorporação dos personagens, ocupando ora a posição de narrador, ora a de personagem que sofria ou realizava as ações. A coleta dos dados foi realizada em local de melhor conveniência do participante, de modo individual e dividida em etapas $A$, B e C. A primeira etapa $(A)$ consistia no preenchimento de um cadastro inicial contendo perguntas fechadas que os participantes preencheram a fim de fornecer informações referentes ao seu nível de escolarização; tempo que faz uso da Libras; convivência com surdos e ouvintes; se os surdos que mantém contato têm domínio da Libras, em que tipo de ambiente mantém contato com surdos e se considera fluente em Libras.

Em seguida, foi aplicada a etapa B: visualização do vídeo com a versão 1 - fábula e questões - e, depois, o preenchimento do gabarito. Na etapa $\mathrm{C}$, foi seguida a mesma orientação: visualização do vídeo com a versão 2 - fábula e questões - e preenchimento do 
http://dx.doi.org/10.5902/1984686X43044

gabarito. Todos os participantes tiveram a opção de pausar o vídeo após a aparição de cada uma das 15 perguntas e das três alternativas de respostas de múltipla escolha $(A, B, C)$ para que pudessem assinalar no gabarito $o$ item considerado correto. Com a finalização das três etapas, foram recolhidos os gabaritos para serem posteriormente utilizados na análise dos dados.

\section{Resultado e Discussão}

No gráfico a seguir, é possível perceber o desempenho dos participantes em cada versão da fábula destacando a evolução da idade e o número de acertos das questões.

Gráfico 1 - Gráfico de acertos (da menor para a maior idade do participante)

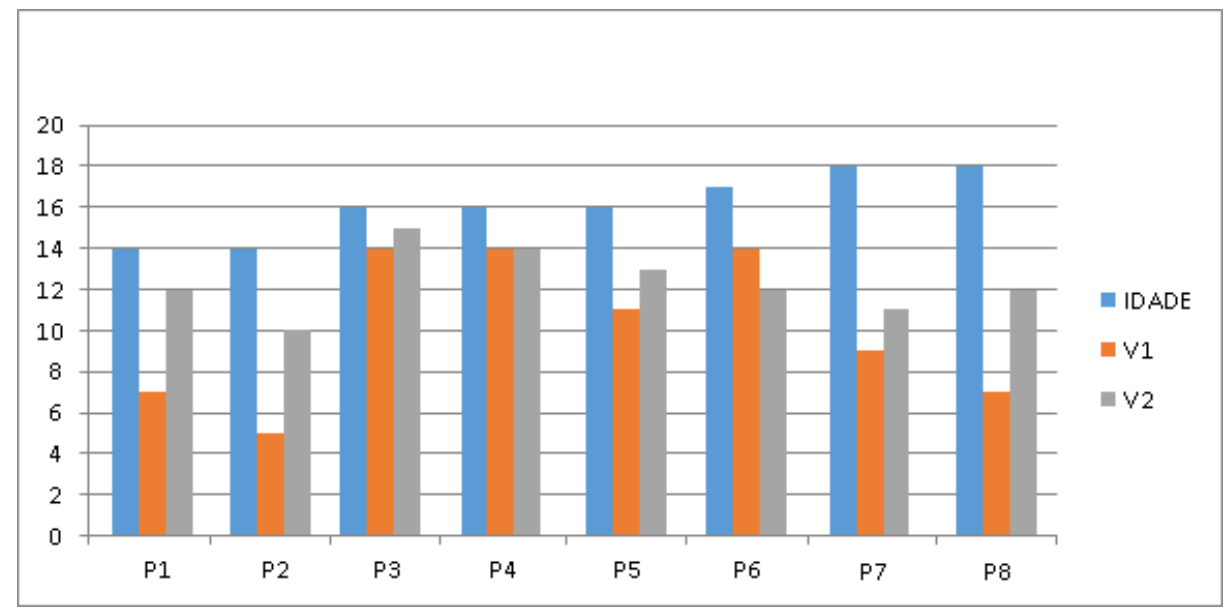

Fonte: Elaboração das autoras (2020).

De forma geral, em relação aos participantes de menor idade (P1 e P2) e que se consideraram com menos domínio em Libras, foi obtido mais êxito na versão 2 da fábula, conforme especulamos. Os participantes com mais idade (P7 e P8) e que se consideraram mais experientes em Libras também tiveram mais acertos nas questões da versão 2 , assim como os participantes mais jovens. Portanto, entre todos os participantes o número maior de acertos deu-se na versão 2 da fábula, pensada inicialmente para obter mais êxito apenas com os jovens com um conhecimento menos consolidado em Libras. No tocante aos acertos por questões, ao analisar a versão 1 constatou-se que todos os participantes acertaram seis das questões apresentadas (as de número 2, 4, 8, 9, 10 e 14), conforme demonstra a tabela a seguir. 
http://dx.doi.org/10.5902/1984686X43044

Tabela 1 - Acertos x Questão (versão 1)

\begin{tabular}{|c|c|c|c|c|c|c|c|c|c|c|c|c|c|c|c|}
\hline Questões & 1 & 2 & 3 & 4 & 5 & 6 & 7 & 8 & 9 & 10 & 11 & 12 & 13 & 14 & 15 \\
\hline \multicolumn{16}{|l|}{ Participantes } \\
\hline \multicolumn{16}{|l|}{ P1 } \\
\hline & & & & & & & & & & & & & & & \\
\hline \multicolumn{16}{|l|}{$\mathbf{P 2}$} \\
\hline & & & & & & & & & & & & & & & \\
\hline \multicolumn{16}{|l|}{ P3 } \\
\hline & & & & & & & & & & & & & & & \\
\hline \multicolumn{16}{|l|}{ P4 } \\
\hline & & & & & & & & & & & & & & & \\
\hline \multicolumn{16}{|l|}{ P5 } \\
\hline & & & & & & & & & & & & & & & \\
\hline \multicolumn{16}{|l|}{ P6 } \\
\hline & & & & & & & & & & & & & & & \\
\hline \multicolumn{16}{|l|}{ P7 } \\
\hline & & & & & & & & & & & & & & & \\
\hline P8 & & & & & & & & & & & & & & & \\
\hline
\end{tabular}

Fonte: Elaboração das autoras (2020).

$\mathrm{Na}$ tabela 2, a seguir, pode-se notar que na versão 2 a quantidade de acertos total acontece para mais itens do que na versão 1 , sete itens e, precisamente, nas questões de número: 4, 5, 6, 9, 10, 11 e 15.

Tabela 2 - Acertos x Questões (versão 2)

\begin{tabular}{|l|l|l|l|l|l|l|l|l|l|l|l|l|l|l|l|l|} 
Questões & 1 & 2 & 3 & 4 & 5 & 6 & 7 & 8 & 9 & 10 & 11 & 12 & 13 & 14 & 15 & 16 \\
\hline Participantes & & & & & & & & & & & & & & & & \\
\hline P1 & & & & & & & & & & & & & & & & \\
\hline P2 & & & & & & & & & & & & & & & & \\
\hline P3 & & & & & & & & & & & & & & & \\
\hline P4 & & & & & & & & & & & & & & & \\
\hline P5 & & & & & & & & & & & & & & & \\
\hline P6 & & & & & & & & & & & & & & & \\
\hline P7 & & & & & & & & & & & & & & & & \\
\hline P8 & & & & & & & & & & & & & & & & \\
\hline
\end{tabular}

Fonte: Elaboração das autoras (2020). 
http://dx.doi.org/10.5902/1984686X43044

Ao relacionar as duas versões, foi identificado que houve cem por cento de acerto nas questões nove e catorze, as quais tratavam sobre aspectos da compreensão de sentido da história contada. Nesse caso, nenhum participante errou essas questões mesmo tendo sido elaboradas de maneiras diferentes para cada uma das versões. Sendo assim, nota-se que houve boa percepção da história e clareza do que se pedia na pergunta. No entanto, em relação aos erros podemos destacar as questões de número 1, 3, 12 e 15 como aquelas que apresentaram maior quantidade de erros. A questão de número 1 tratava sobre o mesmo tipo de conteúdo (identificação dos personagens), tanto na V1 quanto na V2, porém apresentadas com estratégias diferentes. A estratégia da V1 foi usar a forma lexical na terceira pessoa do singular do pronome pessoal ELE/ELA para se referir a águia e também para se referir a tartaruga. O sinal do pronome ELE/ELA é apontado para uma pessoa que pode estar presente ou ausente no discurso.

O pronome ELE/ELA não aparece na V2 nessa mesma questão de número 1. No lugar dele usou-se um classificador para demonstrar que se referia à identificação dos dois personagens. Essas estratégias diferentes na organização da pergunta levaram os participantes a terem resultados diferenciados na mesma questão (número 1) nas duas versões. Houve mais erros na V2 em que se usou o classificador e menos erros na versão 1 em que se utilizou o pronome. Nas tabelas 1 e 2, é possível notar que a questão 01 da V2 possui cinco erros (Tabela 2) e já na V1 há apenas três erros nessa mesma questão (Tabela 1).

A condição de utilizar o recurso pronominal está enquadrada no campo lexical da língua de sinais e não no âmbito gramatical, pois, segundo Oliveira (2018), existe uma diferença entre os domínios lexical e gramatical no que diz respeito às línguas orais e de sinais. $\mathrm{O}$ aspecto gramatical refere-se a distinções gramaticais que são marcadas na morfologia, principalmente por meio de verbos auxiliares e morfemas derivacionais e flexionais. Já o aspecto lexical caracteriza-se por propriedades inerentes ao verbo e a outros itens lexicais empregados pelo enunciador.

Ao se tratar do aspecto lexical na esfera pronominal, é necessário compreender o sentido de dêixis de pessoa. O termo "deixis" tem origem grega e significa o ato de indicar, apontar, mostrar. As autoras Pizzio, Rezende e Quadros (2009), observaram os trabalhos da pesquisadora norte-americana Norine Berenz (1996), que estudou sobre movimentos surdos brasileiros e também sobre a dêixis de pessoa na Libras. Para Berenz (1996), a dêixis de pessoa é realizada tanto nas línguas orais como nas línguas de sinais pelos pronomes 
http://dx.doi.org/10.5902/1984686X43044

pessoais e pelos pronomes possessivos. Na língua de sinais, assim como nas línguas orais, os dêiticos também fazem referência a uma sentença no espaço e no tempo, indicando os participantes de uma comunicação (MEIER, 1990).

No entanto, nas línguas de sinais, existe a diferença espacial pelo fato da referência de pronome ser realizada no mesmo canal de produção (visual - espacial) e por sinais que combinam os traços linguísticos e gestos de apontamento construídos pelos articuladores da língua: mãos e expressão (MOREIRA, 2007).

O sinal para pronome de terceira pessoa do singular segue com o dedo indicador estendido de forma perpendicular à palma da mão, conforme as mudanças na posição da cabeça e da direção do olhar levemente para cima em direção à apontação.

Os pronomes nas línguas de sinais servem para escolher, ao invés de denotar, seus objetos referenciais, assim como acontece com os pronomes nas línguas faladas. Eles fazem isso exatamente como é feito nas línguas faladas, por meio de convenções gramaticais e conversacionais. (BERENZ, 1996).

Concordando com esta afirmativa, a autora Lucinda Ferreira (2010), enfatiza que esses sinais de apontação não são nomes e, sim, pronomes pessoais que substituem e/ou acompanham os sinais lexicais, através do uso do dedo indicador, apontando no espaço para seus referentes. Nesse sentido, Moreira (2007, p. 83), apresenta argumentos que sustentam a ideia de que:

\footnotetext{
Só seria possível distinguir a forma de um sinal para a segunda pessoa da forma de um sinal para a terceira pessoa, se as conversações, nas línguas de sinais, fossem estruturadas fisicamente sempre na mesma maneira. [...] Mas na língua de sinais o enunciatário pode estar em qualquer lugar do espaço físico em que ocorre a conversa e, por isso, não há uma forma fixa de apontar para a segunda pessoa ou para apontar para a terceira pessoa. (MOREIRA, 2007, p. 83)
}

Pensando nisso, é válido ressaltar que não está sendo tratado, neste estudo, de uma situação de conversação com a presença do enunciatário, na qual a direção do sinal muda conforme o lugar associado à conceitualização da entidade e, sim, de uma narrativa gravada com o enunciador sempre na mesma posição de comunicação: com a projeção imaginativa de um enunciatário (o participante que assiste ao vídeo) em frente ao enunciador e a pessoa (personagens da fábula) de quem se fala localizados ora à direita ora à esquerda desse enunciador.

Ainda conforme Moreira (2007), só é possível construir esses diferentes mecanismos que projetam a pessoa, quando se consegue entender que os discursos das línguas naturais são constituídos através de redes de espaços mentais, os quais são definidos pela autora como 
http://dx.doi.org/10.5902/1984686X43044

estratégias cognitivas de estruturação do polo semântico de nossas unidades simbólicas, como as palavras, símbolos, frases, textos e discursos inteiros. Não de maneira isolada, mas através de uma integração entre os espaços mentais.

Para essas concepções, Moreira (2007) traz, em seu estudo, evidências linguísticas de trabalhos que contribuem com a teoria de espaços mentais nas línguas de sinais, especialmente na ASL - Língua de Sinais Americana, como Liddell (1995, 1996, 2000 e 2003) e Liddell e Metzeger (1998). Esses autores apresentam a percepção de que a maior parte dos espaços mentais construídos e organizados nos discursos das línguas de sinais estão relacionados ao espaço físico (e/ou sobrepostos a ele) e o espaço onde está ocorrendo a enunciação.

$\mathrm{O}$ que aconteceu na primeira questão na V1 é que o enunciador representou os personagens da fábula sob a forma de sinais projetados em um ponto fixo no espaço físico de sinalização. Neste espaço limitado, o enunciador, ao associar o sinal nominal para a personagem tartaruga em um local no espaço (esquerda), utiliza também um marcador no mesmo espaço de sinalização para marcar o pronome ELE/ELA para referir-se à tartaruga. Em seguida, ao sinalizar à personagem águia em outro local no espaço (direita), também marca neste espaço físico o pronome ELE/ELA para referir-se à águia para se referir a águia.

Como são dois personagens diferentes, foram utilizadas duas marcas no espaço de sinalização. Este aspecto acontece com os sinais pronominais presentes nas línguas sinalizadas da mesma forma como acontece com os signos pronominais nas línguas orais, pois, os signos pronominais não servem para nomear coisas e sim para indicar coisas simplesmente pelo fato de os pronomes e nomes serem elementos linguísticos de naturezas diferentes.

Sendo assim, os participantes deste estudo tiveram melhor desempenho nesta questão na versão 1, que ancorou o pronome pessoal indicando no discurso a quem o enunciador estava se referindo na ação (a águia e a tartaruga). Portanto, pode-se notar que fez mais sentido para os participantes perceberem a informação contida na primeira pergunta da V1, não apenas por ter sido utilizado um recurso pronominal em seu modo formal linguístico, mas também pela direção do apontamento para um local que não estava associado à conceitualização, nem do sinalizador, nem de seu enunciatário, mas sim da terceira pessoa do discurso.

Ainda sobre as questões que tiveram maior número de erros, pode-se destacar a questão de número três, a qual também abordou o mesmo conteúdo nas duas versões: sobre um 
http://dx.doi.org/10.5902/1984686X43044

determinado desejo que a tartaruga apresentou na história e que o participante precisaria precisa identificar como esse sentimento foi demonstrado. $\mathrm{Na}$ alternativa de letra $\mathrm{A}$, informava que a tartaruga estava tendo um sonho; na alternativa de letra $B$, informava que ela estava tendo um pensamento; e na alternativa de letra $C$, informava que a tartaruga estava procurando algo. Dessa maneira, nas duas versões as alternativas trouxeram os mesmos verbos (sonhar, pensar e procurar) para ilustrar cada opção de resposta.

Tais verbos são muito utilizados na Libras desde o aprendizado de nível básico da língua, portanto, podem ser considerados como conhecidos pelos participantes. No entanto, 0 enunciador da pergunta na V1 usa mais sinais, tornando a pergunta mais longa por trazer mais elementos do texto e, assim, mais informações do que aquelas apresentadas na V2, na qual o enunciador elabora a questão de modo mais curto, porém utilizando classificadores, dentre eles um balão de pensamento que sinalizava o desejo/sentimento da tartaruga.

Para tal conjuntura, Silva (2014) esclarece que alguns elementos semióticos cognitivos e interacionais têm função participativa na construção de significados e potencializa o entendimento de uma narrativa. Para o autor:

\begin{abstract}
As demonstrações desses elementos criam dinamicamente representações visuais icônicas dos referentes da narrativa (entidades, personagens, estados, processos ou ações), de modo que os interlocutores são capazes de perceber os aspectos representados como se estivessem presenciando o próprio referente. [...]. Seja em língua oral ou sinalizada, esse tipo de demonstração envolve 0 uso de expressões faciais para caracterizar as personagens e imitações de ações e de posturas corporais das personagens; além desses recursos, o narrador ainda usa modulações de voz e os sinalizadores, modulações em sinais, para demonstrar diversos aspectos icônicos em relação à história que estão contando. (SILVA, 2014 p.3).
\end{abstract}

Por essa perspectiva, constata-se que, além dos elementos concretos da narrativa (personagens, ações, cenários, etc.), as demonstrações de elementos abstratos, como os que foram usados na V2, serviram para ilustrar alguns aspectos visuais do que estava sendo descrito na narrativa, ajudando na organização do discurso e, consequentemente, na melhor compreensão do que estava sendo enunciado para o interlocutor. Já o recurso da V1 de utilização de muitas informações na elaboração da pergunta não favoreceu o entendimento da maioria dos participantes. Assim, nessa questão (questão 03), foram constados apenas três erros na V2 (37.5\%), enquanto na V1 sete dos oito (87.5\%) participantes erraram a resposta.

A questão de número 12 na V1 corresponde à questão número 13 da V2 por tratarem o mesmo assunto nas duas versões: a altura do voo da águia. Na alternativa $A$, a águia voou 
http://dx.doi.org/10.5902/1984686X43044

acima das nuvens; na alternativa B, a águia voou na altura das nuvens; e, na alternativa $\mathrm{C}$, a águia voou próximo ao chão.

Na versão 1, apenas dois participantes erraram a resposta (25\%), enquanto, na V2, seis (75\%) participantes erraram. Embora a pergunta da questão 12 fosse a mesma nas duas versões (V1 e V2), houve diferença no formato do discurso enunciado para realizar a pergunta. $\mathrm{Na}$ V2, a enunciação da pergunta mostrou-se mais detalhada por elementos indeterminados, essa construção de discurso, possivelmente, causou dúvida nos participantes e imprecisão na resposta. De outro modo, na V1, foi utilizado um formato mais preciso de produção da pergunta, uma pergunta mais objetiva, sem floreios, apresentando as opções (alternativas: $A, B, C$ ) de maneira mais direta.

Sendo assim, é indispensável atentar para o fato de que "a língua de sinais é muito direta" (ALBRES, 2013, p. 301) e mais sintética, por explorar intensamente a simultaneidade na constituição dos sinais e dos enunciados e não depender substancialmente do uso de termos gramaticais como artigos e conjunções, por exemplo.

A condição de utilizar vários elementos e uma grande quantidade de sinais simultaneamente tende a interferir no entendimento da mensagem transmitida. Sobre esse ponto, um estudo acerca dos efeitos do processo de produção de informação simultânea em língua de sinais, de Rodrigues (2013), explica que a taxa de produção reduzida das línguas de sinais encoraja a sobreposição de diversas informações simultaneamente, o que é possível devido à morfologia das línguas de sinais. No entanto, no tocante à taxa de informação proposicional em relação ao tempo, enunciados possuem uma densidade de informação em cada sinal. Um único sinal monossilábico é tipicamente polimorfêmico. Desse modo, a informação não é alcançada pela velocidade da série de segmentos e morfemas, mas pela quantidade da sequência de produção morfológica. Por isso, pensar em estratégias para um enunciado direto é imprescindível para que a informação não se perca como ocorreu com essa questão na V2.

A questão de número 15 da V1 corresponde à questão 16 da V2 e nela o enunciador faz uma pergunta sobre o local em que a tartaruga caiu. Se a tartaruga caiu na pedra (alternativa A); se ela caiu no chão (alternativa B); ou se caiu na água (alternativa C). Posto isso, na V1, apenas dois participantes acertaram (25\%) seis participantes erraram e, na V2, foram apenas três $(37,5 \%)$ cinco participantes erraram. Pode-se considerar que os participantes apresentaram dificuldade com o entendimento da questão, mas em que aspecto? 
http://dx.doi.org/10.5902/1984686X43044

Ao analisar cada versão (V1 e V2), depreende-se que não houve grandes diferenças entre a apresentação dessa questão nas duas versões, pois os enunciadores sinalizaram em Libras de maneira bem semelhante. A oração foi formulada usando praticamente a mesma ordem gramatical no que diz respeito à sintaxe, portanto não ocorreram divergências consideradas discrepantes como nas outras questões. Pelo contrário, essa foi a questão com sinais e classificadores mais parecidos e, em relação à morfologia, na maioria dos momentos foram usados até os mesmos sinais. No entanto, foi a questão em que o maior número de participantes errou nas duas versões das perguntas.

O aspecto relevante que se pode atribuir para a quantidade de erros nessa questão é de que os participantes não obtiveram êxito em relação à compreensão do sentido textual do desfecho da fábula, possivelmente, por falha da condição necessária de memória sobre os elementos essenciais para o desfecho da história e que também eram quesitos indispensáveis para a obtenção da resposta correta.

Quanto à memória, os autores Baddeley e Hitch (1974) e Baddeley (2011, apud NOGUEIRA, 2018) argumentam que este é um fator que compõe áreas de funcionalidades específicas para o entendimento. Uma delas, e que o autor trabalha com mais profundidade, é a memória de "trabalho" (MT), um sistema de processamento de informações para atuar numa atividade cognitiva complexa, como por exemplo a compreensão, a aprendizagem e raciocínio. A memória de trabalho é composta por um sistema com três componentes: o controle executivo, cuja função é a de controlar a atenção; a alça fonológica e esboço visuoespacial, que são especializados no processamento e manipulação de quantidades limitadas de informações de natureza específica: acústicas, visuais, espaciais e que diferem dos modelos de memória de curta duração, cuja ênfase é o armazenamento.

Conforme os autores (op.cit.), a memória de trabalho tem implicações no processamento da linguagem, assim como há distinção de processamento das informações apresentadas auditivamente e visualmente. Enquanto as informações auditivas acessam diretamente o armazenamento fonológico, as informações visuais precisam de uma articulação subvocal (recitação) que permite o acesso à alça fonológica. Seguindo nessa esteira de pensamento, temos as línguas de sinais que são equivalentes às demais línguas de modalidade oralauditiva, por possuir características linguísticas como morfologia, sintaxe, semântica, etc. (QUADROS; KARNOPP, 2004). Sob essa perspectiva, Nogueira (2018, p. 36) argumenta que 
http://dx.doi.org/10.5902/1984686X43044

informações baseadas nas características fonológicas dos sinais: configuração de mãos, orientação, localização, movimento e expressão facial. (NOGUEIRA, 2018 p. 36. grifo meu.)

Nesse sentido, o autor reitera que a memória baseada em sinais sofre interferência do tipo de articulação exigida pelo sinal, da mesma forma que a memória fonológica sofre interferência do comprimento da palavra. Porém, não se pode atribuir aos surdos uma capacidade reduzida de memória de trabalho, visto que existe superioridade de performance dos surdos quando a tarefa envolve estímulos visuoespaciais e superioridade de performance dos ouvintes quando a tarefa envolve estímulos fonológicos (NOGUEIRA, 2018; HIRSHORN et. al. 2012; BOUTLA et. al. 2004).

Por essas constatações, a elevada quantidade de erros na questão de número 15, na V1, equivalente a questão de número 16 na V2, não teria ocorrido por interferência da modalidade linguística da língua de sinais, dado que os sinais utilizados pelos enunciadores nas duas versões foram praticamente os mesmos, mas sim, provavelmente, pela capacidade da memória de trabalho dos participantes surdos.

Destarte, a ideia inicial da presente pesquisa, que considerava a V1 como mais complexa em relação a versão 2, não se mostrou verdadeira para todas as questões. Caberia ainda uma análise do nível de acesso e conhecimento da Libras por cada um dos participantes para um adensamento das constatações, contudo esse tema será tratado em estudos futuros.

\section{Considerações finais}

As análises realizadas podem ajudar por um lado a aperfeiçoar a prova (ferramenta), mas também podem ajudar a entender como jovens surdos pensam/processam a língua de sinais e ainda quais aspectos podem constituir dificuldades/barreiras, e quais aspectos podem figurar como facilitadores para a compreensão discursiva.

A análise das respostas e a identificação do que pode ter interferido para respostas mais ou menos corretas podem ajudar a melhoria das práticas pedagógicas no que tange ao ensino da língua de sinais e ainda no que tange ao trabalho com a compreensão e interpretação daquilo que é enunciado nessa língua pela escola.

Uma atividade avaliativa da compreensão de Libras pode revelar o que figura como mais ou menos complexo para jovens surdos (em idade de frequentarem anos finais da educação básica), favorecendo o desenvolvimento de ações de ensino atentas a essas características.

A ferramenta de avaliação aqui apresentada encontra-se em desenvolvimento e pesquisas como esta podem favorecer seu aperfeiçoamento. Além disso, este estudo indica a 
pertinência de realizar a aplicação da ferramenta com um número maior de sujeitos e de diferentes faixas etárias, visando aperfeiçoar a ferramenta como um todo. São os usuários surdos que, atuando com a ferramenta, podem indicar melhor a adequação ou não do instrumento e o que se pode aprender com ele no sentido de aperfeiçoar as práticas pedagógicas.

Os resultados deste trabalho de pesquisa permitiram identificar e analisar ainda pontos fortes e fracos dos usuários de língua de sinais, nos aspectos de compreensão em Libras. Esse conhecimento pode auxiliar professores que atuam com alunos surdos na criação de estratégias, visando o desenvolvimento linguístico do seu alunado.

\section{Referências}

ALBRES, Neiva de Aquino. Mesclagem de voz e tipos de discurso no processo de interpretação da língua de sinais para o português oral. Revista Cadernos de Tradução, v2, ำ26, Florianópolis, Brasil, p. 291-306. 2010. Disponível em:

https://www.porsinal.pt/index.php?ps=artigos\&idt=artc\&cat=16\&idart=113. Acesso em: 19 fev. 2019.

ANTUNES, Irandé. Muito além da gramática: por um ensino de línguas sem pedra no caminho. Parábola Editorial. São Paulo 2007.

BADDELEY, Alan David; ANDERSON, Michael; EYSENCK, Michel William. Memória. Porto Alegre: Artmed. 2011.

BARBOSA, Felipe Venâncio; LICHITIG, Ida. Protocolo do perfil das habilidades de comunicação de crianças surdas. Revista de estudos de linguagem, Belo Horizonte, v. 22, n. 1, p. 95-118, jun. 2014.

BERENZ, Norine Frances. Person and deixis in Brazilian sign language. 1996. Dissertation (PhD). University of California, Berkeley, 1996.

BRASIL. Regulamenta a Lei no 10.436, de 24 de abril de 2002, que dispõe sobre a Língua Brasileira de Sinais - Libras. Decreto no 5.626, de 22 de dezembro de 2005. Brasília, DF, 2005.

BOUTLA, Mrim. et al. Short-term memory span: insights from sign language. Nature Neuroscience. v. 7, p. 997-1002. 2004. Disponível em:

https://www.nature.com/articles/nn1298. Acesso em: Jul. 2019.

FERREIRA, Antônio Gomes. O sentido da educação comparada: uma compreensão sobre a construção de uma identidade. Revista Educação, Porto Alegre, v. 31, n. 2, p. 124-138, maio/ago. 2008. Disponível em:

http://revistaseletronicas.pucrs.br/ojs/index.php/faced/article/view/2764. Acesso em: 3 jun 2019. 
http://dx.doi.org/10.5902/1984686X43044

FERREIRA, Lucinda. Por uma gramática de língua de sinais. São Paulo: Cultrix, 2010.

GÓES, Lucia Pimentel. Introdução à literatura infantil e juvenil. 2. ed. São Paulo: Pioneira, 1984.

HIRSHORN, Elizabeth; FERNANDEZ, Nina Moix; BAVELIER, Daphne. Routes to short- term memory indexing: Lessons from deaf native users of American Sign Language. Cognitive Neuropsychology, 29(1-2), 85-103. 2012.

LACERDA, Cristina Broglia Feitosa. et al. Educação inclusiva bilíngue para alunos surdos: pesquisa e ação em uma rede pública de ensino. In: LACERDA, Cristina Broglia Feitosa.; SANTOS, Lara Ferreira.; MARTINS, Vanessa Regina de Oliveira (Org). Escola e Diferença: Caminhos para a educação Bilíngue de Surdos. São Carlos: Edufscar, 2016. p. 13-28.

LACERDA, Cristina Broglia Feitosa. et al. Instrumento de avaliação de textos narrativos em língua de sinais. Universidade de Barcelona (I+D EVALOE_SSD 2015- 2018) e CREDA PereBarnils. (C) 2018 (no prelo).

LIDDELL, Scott. Grammar, gesture and meaning in American Sign Language.

Cambridge: Cambridge University Press. 2003.

LOPES, Maura Corcini. Surdez \& Educação. Belo Horizonte: Autêntica, 2007.

MEIER, Richard. Person deixis in American Sign Language. In: Fischer, S: Siple. P. (Eds.). Theoretical issues sign language research. Linguistics. Chicago: University of Chicago Press, v. 1, p. $175-190.1990$.

MOREIRA, Renata Lucia. Uma descrição da dêixis de pessoa na língua de sinais brasileira: Pronomes pessoais e verbos indicadores. Dissertação (Pós-graduação em semiótica e linguística geral) Universidade de São Paulo - USP. 2007

MULLER, Janete Inês. et al. Educação Bilíngue para Surdos: Interlocução entre Políticas Linguísticas e Educacionais. Nonada: Letras em Revista, Porto Alegre, vol. 2, n.1. p.115.out. 2013.

NOGUEIRA, Newton da Rocha. Teste de memória de trabalho em Libras: Proposta e considerações. Dissertação (Programa de Pós-graduação em Letras e Linguística) Faculdade de Letras da Universidade Federal de Goiás. 2018.

OLIVEIRA, Fernanda Alves. Distinção entre aspecto lexical e aspect gramatical na língua brasileira de sinais. Dissertação (Pós-graduação em Letras) Universidade Federal do Paraná. 2018.

PIZZIO, Aline Lemos. et al. Tópicos de linguística aplicados à Língua de Sinais: Semântica e Pragmática. Coleção Letras Libras. Universidade federal de Santa Catarina, 2009. Disponível em:

http://www.libras.ufsc.br/colecaoLetrasLibras/eixoFormacaoEspecifica/linguaBrasileiraDe SinaisV/assets/576/TEXTO_BASE_-_LIBRAS_V.pdf . Acesso em: 23 de Fev. 2020. 
QUADROS, Ronice Muller; CRUZ, Carina Rabello. Língua de Sinais: Instrumentos de Avaliação. Porto Alegre, 2011.

QUADROS, Ronice. Muller; KARNOPP, Lodenir Becker. Língua de sinais brasileira: estudos linguísticos. Porto Alegre: Artmed. 2004.

ROCHA, Justiniano José. Fábulas (imitadas de Esopo e La Fontaine). Edição Ridendo Castigat Mores. Versão para eBook. eBooksBrasil.org. Disponível em:https://www.portalentretextos.com.br/download/livros-nline/fabulas_esopo_1.pdf Acesso em 21 de Nov. 2019.

RODRIGUES, Carlos Henrique. A interpretação simultânea entre línguas e modalidades. Revista Veredas On-Line. Programa de Pós-Graduação em Linguística da Universidade Federal de Juíz de Fora - MG, v.2, p. 266-286, 2013. Disponível em: http://www.ufjf.br/revistaveredas/files/2014/04/14\%C2\%BA-ARTIGO.pdf Acesso em 19 Mar. 2020.

SILVA, João Paulo. Narrativas sinalizadas em Libras. Dissertação (mestrado em semiótica e linguística geral) Universidade de São Paulo - USP. 2014.

SILVA, Simone Goncalves Lima. Consequências da Aquisição Tardia da Língua Brasileira de Sinais na Compreensão Leitora da Língua Portuguesa, como Segunda Língua, em Sujeitos Surdos. Revista Brasileira de Educação Especial, Marília, v. 21, n. 2, p. 275- 288, abr.-jun. 2015. Disponível em: http://www.scielo.br/pdf/rbee/v21n2/1413-6538-rbee-21-02-00275.pdf. Acesso em 21 jun. 2019.

SKLIAR, Carlos. (Org). A Surdez: um olhar sobre as diferenças. Porto Alegre: Editora Mediação,1998.

WILSON, Margaret; EMMOREY, Karen. A “word length effect” for sign language: Further evidence for the role of language in structuring working memory. Memory \& Cognition, 26(3), p.584-590.1998. Disponível em: https://link.springer.com/article/10.3758/BF03201164. Acesso em 18 jun. 2019.

\section{Notas}

\footnotetext{
${ }^{1}$ Atribuída a Esopo.

2 Em uma pesquisa realizada por Wilson e Emmorey (1998) com surdos usuários da Língua Americana de Sinais (ASL) como primeira língua foi identificado o efeito de similaridade fonológica. O experimento continha sinais que se pareciam e sinais que eram diferentes quanto ao parâmetro configuração de mãos e, com esse estudo, a "Alça de Sinais" foi detectada.
}

\section{Correspondência}

Mariana Peres de Morais - Universidade Federal de São Carlos, Rodovia Washington Luiz, s/n, São Carlos, São Paulo - Brasil.

CEP: $13565-905$

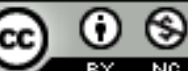

4.0 International (CC BY-NC 4.0) 